\title{
Innovative method to diagnose Coronary Cameral fistula by Contrast Echocardiography
}

\author{
Moustafa Eldeib ${ }^{1}$, Fatema Qaddoura², Marawan Sadek ${ }^{2}$, Donya Alhassan², and Reda \\ Abuelatta $^{3}$ \\ ${ }^{1}$ Al-Azhar University Faculty of Medicine \\ ${ }^{2}$ King Fahd Military Medical Complex \\ ${ }^{3}$ Madinah Cardiac Center
}

June 4, 2020

\begin{abstract}
Introduction: Coronary artery fistula $(\mathrm{CAF})$ is a rare cardiac anomaly that typically presents as a continuous murmur in an otherwise asymptomatic patient. Occasionally, it can result in congestive heart failure or bacterial endocarditis. Objective: To better delineate the course of coronary artery fistula for the first time, using the SonoVue contrast agent during transthoracic echocardiography. Method and results: A referred 46-year-old male with a known history of dyspnea on exertion for a period of almost three months was admitted to the hospital with progressive dyspnea, and assessed under suspicion of CAF. CAF, was seen with a coronary angiogram, but the exact entry point in the left ventricle or left atrial wall could not be determined. CT angiography also failed to establish the exact point of entrance to LV (left ventricle), so CAG (coronary angiography) was repeated with SonoVue contrast agent injected into LM (Left main) while using a Siemens echocardiography machine. Multiple views were obtained during the injection, and revealed unusual flow in the left ventricle just below the PML (posterior mitral leaflet) postero-lateral and passing through the fistula to LV. Conclusion: Contrast Enhanced Echocardiography is thought to be more sensitive and in affording an accurate delineation of CAF drainage into cardiac chambers, and can be utilized in a direct precise and safe way.
\end{abstract}

\section{Introduction}

Congenital CAF is an uncommon cardiac anomaly that usually presents with a continuous murmur in otherwise asymptomatic patients (1). Occasionally, it leads to congestive heart failure or bacterial endocarditis (1-3). If fistulas remain undetected or untreated in childhood, they reportedly $(1,3)$ become symptomatic more frequently in adulthood due to chronic volume overload and myocardial ischemia. Although spontaneous closure can occur sporadically $(4,5)$, elective surgical closure is the preferred mode of treatment $(1$, $3,6,7)$.

A large fistula can occasionally appear as a mass lesion on echocardiography, but cannot easily be confirmed. Here, we report a new diagnostic approach to identifying CAF, using a contrast agent injected into the left coronary artery and transthoracic echocardiography. The case described related to a 46-year-old male suffering from dyspnea with turbulent flow in the left ventricle.

\section{CASE REPORT}

A 46-year-old male was admitted to hospital with progressive dyspnea. He reported suffering from dyspnea upon exertion for 3 months and had been referred from another hospital for further review due to suspicion of coronary fistula, which was present on a coronary angiogram. It had previously not been possible to 
determine the exact entrance point in the left ventricle or the left atrial wall. No abnormal findings had been observed using an initial chest posterior-anterior view and electrocardiogram.

Investigations: Transthoracic and trans-esophageal echocardiography revealed severe LV systolic dysfunction, moderate MR (Mitral Regurge), and with agitated saline small PFO (patent foramen ovale) was observed with TEE (Trans-Esophageal Echocardiography) between the LA (Left Atrium) and the RA (Right Atrium).

CT angiography was performed, delineating the course of the fistula, but did not provide detailed information about the site of drainage into the cardiac chamber (figure 4).

Therefore, a further coronary angiogram was performed (figure 5) using the SonoVue contrast agent (injection of $1.0 \mathrm{ml}$ SonoVue diluted with $9.0 \mathrm{ml}$ normal saline, and injected into LM), at the same time as using a Siemens echocardiography machine. Multiple views were obtained with the injection, and found unusual flow in the left ventricle just below the PML postero-lateral and passing through fistula to LV (figures 1 and 3 ) and at the systolic phase with MR to LA and through PFO to RA and RV (figure 2).

Treatment: After consultation with the heart team, the decision was made to close it. The antegrade approach was used with percutaneous closure with coils. Immediately after closure, the patient's MR improved.

\section{Discussion}

A CAF affects communication between one of the coronary arteries and a cardiac chamber or vein. CAFs are present in $0.2 \%$ of patients undergoing diagnostic cardiac catheterization. (8)

The right and left coronary arteries are involved in 55 and $35 \%$ of cases, respectively, with involvement of both vessels in just $5 \%$ of cases. (2) The arteries serve as a shunt between the coronary system and the cardiac chamber into which they drain. The most common drainage sites are at the right ventricle ventricular fistulae and are exceedingly rare with the incidence being reported as $1.2 \%$ of all coronary artery fistulae. (9) Large shunts may present with pulmonary edema, pulmonary hypertension, infective endocarditis, rupture, or thrombosis of the fistula, and associated arterial aneurysm or myocardial ischemia distal to the fistula ('myocardial steal phenomenon'.) (9)

There are several possible reasons why CAF cannot be visualized directly using transthoracic echocardiography. The CAF may be distally positioned in the coronary circulation, and could be of smaller caliber. This can make them much more difficult to detect, particularly during ventricular systole. However, it is possible to visualize them with contrast when a higher MI (Mechanical Index) is used. This supports visualization of both the myocardial tissue and the contrast agent simultaneously.

The safety of contrast agents (including SonoVue) has been reported previously. It has been used safely during septal ablation in patients with hypertrophic obstructive cardiomyopathy (14). These agents have a good safety profile for use in both cardiac and abdominal ultrasound applications. The incidence of severe adverse reactions to ultrasound contrast agents is no greater, and may be lower than that reported for the contrast agents commonly used in other cardiac imaging tests. (8)

Previously, CAF have been diagnosed with aortography, (10) coronary angiography, (11) and coronary CT. (13) Although there has been a case of color Doppler assessment of a CAF, (12) we cannot readily confirm them with echocardiography. In this study, we employed a new and simple diagnostic approach for CAF using a contrast agent. This assisted with the diagnosis, because it clarifies typical turbulence flow, as it appears in the left ventricle. The use of intraprocedural contrast echocardiography results in an improved procedure and thereby patient outcomes, by shortening the procedure and fluoroscopy time. Contrast echocardiography at the time of aortography proves extremely valuable in both opacifying the coronary arteries and determining which chambers the fistula connects to.

The value of localizing the site of drainage of the fistula is high to the interventional cardiologist, when attempting to close it. 


\section{Conclusion}

Contrast enhanced echocardiography has been used to diagnose CAF in adults, and is thought to be highly sensitive and provide precise and accurate delineation of the CAF drainage into cardiac chambers safely.

This research did not receive any specific grant from any funding agency in the public, commercial or notfor-profit sector.

There is no conflict of interest.

The co-author confirms my findings, and gave me permission and responsibility to report on the patient.

\section{References:}

1. Neufeld HN, Schneeweis A, eds. Congenital coronary artery fistula. In: Coronary Artery Disease in Infants and Children. Philadelphia: Lea \& Febiger, 1983:31-58.

2. Start TJ, Bowman FO, Hordof AJ. Congestive heart failure in a newborn secondary to coronary artery-left ventricular fistula. Am J Cardiol 1986; 58:366-7.

3. Liberthson RR, Sagar K, Berkoben JP, Weintraub RM, Levine FH. Congenital coronary arteriovenous fistula. Circulation 1979;59:849-53.

4. Hackett D, Hallidic-Smith KA. Spontaneous closure of coronary artery fistula. Br Heart J 1984;52:477-9.

5. Mahoney LT, Schieken RM, Lauer RM. Spontaneous closure of a coronary artery ftstula in childhood. Pediatr Cardiol 1982;2:31 l-2.

6. Lowe JE, Newland Oldham H, Sabiston DC. Surgical management of congenital coronary artery fistulas. Ann Surg 1981;194:373-80.

7. Kirklin JW, Barratt-Boyes BG. Congenital anomalies of the coronary arteries. In: Kirklin JW, BarrattBoyes BG, eds: Cardiac Surgery. New York: John Wiley \& Sons, 1986:945-55.

8. Bulut S, Al Hashimi HMM, Gehlmann HR. Multiple Coronary Artery Fistulae or Thebesian Veins? Heart 2007;93:1267.

9. Armsby LR, Keane JF, Sherwood MC, Forbess JM, Perry SB, Lock JE. Management of coronary artey fistulae: patient selection and results of transcatheter closure. J Am Coll Cardiol 2002;39;1026-32.

10. Kim YH, Lee SH, Kang CH, et al. A case report of coronary arteriovenous fistula. Korean Circ J. 1982;12:189-192.

11. Lee SJ, Her SH, Jin SW, et al. A case of bilateral coronary to pulmonary artery fistulas associated with severe aortic regurgitation. Korean Circ J. 2008;38:331-334.

12. Choi SH, Seo HS, Oh SJ, et al. A case of multiple coronary artery-left ventricular microfistulae demonstrated by transthoracic Doppler echocardiography. Korean Circ J. 2003;33:338-342.

13. Zenooz NA, Habibi R, Mammen L, Finn JP, Gilkeson RC. Coronary artery fistulas: CT findings. Radiographics. 2009;29:781-789. [PubMed].

14. Ehab Cherif, Sami Ghazal. Alcohol Septal Ablation after Suboptimal Surgical septal Myomectomy.Case Journal 2018.

\section{Hosted file}

image NEW.docx available at https://authorea.com/users/329722/articles/456650-innovativemethod-to-diagnose-coronary-cameral-fistula-by-contrast-echocardiography 